\title{
Effects of Manure and Synthetic Fertilizer with Residue Returning on Soil Organic Carbon Storage; Interactions with Intra-Aggregate Pore Structure and Water Stable Aggregates in High Input Cropping System: A Review
}

\author{
P. K. Singh ${ }^{1 *}$, R. K. Naresh ${ }^{2}$, U. P. Shahi ${ }^{3}$, S. S.Tomar ${ }^{4}$, R. B. Singh ${ }^{5}$, \\ K. G. Yadav', Mukesh Kumar ${ }^{1}$, Mukesh Kumar ${ }^{6}$, A. K. Mishra ${ }^{7}$, \\ Vipin Kumar Sharma ${ }^{8}$ and Rakesh Tiwari ${ }^{9}$
}

\author{
${ }^{1}$ Directorate of Extension, ${ }^{2}$ Department of Agronomy, ${ }^{3}$ Department of Soil Science and \\ Agricultural Chemistry, ${ }^{6}$ Directorate of Research, Sardar Vallabhbhai Patel \\ University of Agriculture \& Technology, Meerut (U. P.), India \\ ${ }^{4}$ R.V.S. Krishi Vishwa Vidyalaya - ZARS, Morena, India \\ ${ }^{5}$ All India Coordinated Project on Use of Saline Water in Agriculture, \\ R.B.S. College bichpuri, Agra (U. P.), India \\ ${ }^{7}$ Krishi Vigyan Kendra, Hapur U.P.) India \\ ${ }^{8}$ Krishi Vigyan Kendra, G.B.Nagar, (U.P.) India \\ ${ }^{9}$ Krishi Vigyan Kendra, Hastinapur, Meerut (U.P.) India
}

*Corresponding author

\section{A B S T R A C T}

\section{Keywords}

Soil organic carbon, Light fraction carbon, Water soluble carbon, Particulate organic matter

Article Info

Accepted:

20 May 2020

Available Online:

10 June 2020
Soil organic carbon (SOC) and its labile fractions are strong determinants of chemical, physical, and biological properties, and soil quality. The concentration of SOC at different depths in $0-60 \mathrm{~cm}$ soil profile was higher under NP+FYM follow by under NP+S, compared to under CK. The SOC storage in $0-60 \mathrm{~cm}$ in NP+FYM, $\mathrm{NP}+\mathrm{S}, \mathrm{FYM}$ and NP treatments were increased by $41.3 \%, 32.9 \%, 28.1 \%$ and $17.9 \%$, respectively, as compared to the CK treatment. Organic manure plus inorganic fertilizer application also increased labile soil organic carbon pools in $0-60 \mathrm{~cm}$ depth. The average concentration of particulate organic carbon (POC), dissolved organic carbon (DOC) and microbial biomass carbon (MBC) in organic manure plus inorganic fertilizer treatments $\mathrm{NP}+\mathrm{S}$ and $\mathrm{NP}+\mathrm{FYM}$ ) in $0-60 \mathrm{~cm}$ depth were increased by $64.9-91.9 \%, 42.5-56.9 \%$, and $74.7-99.4 \%$, respectively, over the $\mathrm{CK}$ treatment. After $18 \mathrm{yr}$, manure increased the OM level of the whole soil and favored formation of slakingresistant macro-aggregates $(250-1000 \mu \mathrm{m})$. This effect was primarily a result of the OM added by the manure. In contrast, NPK fertilizer did not affect soil OM level or macro-aggregation. The increase in OM induced by manure application was observed primarily in macro-aggregates, and both as mineral-associated and particulate OM. However, manure did not change OM located in the fraction $<53 \mu \mathrm{m}$ confirming that recently deposited OM preferentially accumulates within the aggregate structure and not in the finely or non-aggregated material. The mean soil organic carbon storage of the $0-60 \mathrm{~cm}$ soil layers were significantly increased with $\mathrm{H}, \mathrm{M}$, and $\mathrm{L}$, by $21.40 \%, 20.38 \%$ and $8.21 \%$ compared with CK, respectively. Straw incorporation increased $0.25 \mathrm{~mm}$ waterstable macro-aggregates level, geometric mean diameter, mean weight diameter and the aggregate stability, which were ranked in order of increasing straw incorporation rates: H/M $>L>C K$. Therefore review study shown that most of the $\mathrm{C}$ in cattle manure is composed of coarse particles, we hypothesize that manure-derived OM first enters the soil primarily as particulate material, then, during decomposition, is transformed within the aggregate structure into mineral associated material thereby contributing to aggregate stabilization. 


\section{Introduction}

Soil organic carbon (SOC) is a key indicator of soil fertility, and changes in SOC content leads to soil aggregation modification. SOC influences soil aggregation because of its binding function (Tisdall and Oades, 1982), and in turn, soil aggregation affects SOC sequestration. As such, SOC enhancement is a strategy that can be used to mitigate climate change (Almaraz et al., 2009). In this regard, soil aggregation and SOC sequestration has gained increased research attention. In agricultural ecosystems, among many factors those affect aggregation process and SOC sequestration, the alternation in land use and fertilizer management practices might be of the most important ones. Both management practices exert profound direct and indirect effects on the growth and biodiversity of vegetation and microbial organisms, thereby increasing the organic input into the soil. Arable land abandonment has been reported one of the most important global land use strategies in the past decades (Raiesi 2012). Several studies showed that cropland abandonment increases the amount of macroaggregates $(>0.25 \mathrm{~mm})$ and improves aggregate stability in the top soil layer (0-10, 0-20 and 0-30 cm) over time (Li and Pang 2010; Raiesi 2012).

Labile fractions of $\mathrm{C}$ in soils, such as microbial biomass $\mathrm{C}$ (MBC), water soluble $\mathrm{C}$ (WSC), light fraction $\mathrm{C}$ (LFC) and particulate organic matter (POM) can respond rapidly to changes in $\mathrm{C}$ inputs (Bolinder et al. 1999). Thus, these have been suggested as early indicators of the effects of land use changes on soil organic matter quality (Gregorich et al., 1994). In general, the labile $\mathrm{C}$ pool has a greater turnover rate of several weeks to months or years compared with more recalcitrant pools (Paul et al., 2001) and therefore, labile $\mathrm{C}$ pool is much smaller in size. The WSC, a labile C pool, is the main energy source for soil microorganisms, a primary source of mineralizable $\mathrm{N}, \mathrm{P}$, and $\mathrm{S}$, and it influences the availability of metal ions in soils by forming soluble complexes (Stevenson, 1994).While the MBC constitutes living micro-organisms that are smaller than 5-10 $\mu \mathrm{m}^{3}$, these microorganisms help in aggregate formation by producing gums and mucilage's (Watts et al., 2005). The LFC (free or uncomplexed) is considered to include decomposing plant and animal residues that have rapid turnover rate and thus can be an important source of plant nutrients (Wander et al., 1994), however, LFC has lower specific density than soil minerals. The differences in $\mathrm{C}$ fractions resulting from different management practices can provide knowledge about the mechanisms of $\mathrm{C}$ sequestration (Six et al., 2002).The management practices that increase the sequestration of $\mathrm{C}$ in soils are also found to have favorable effects on soil structure (Rasool et al., 2007). The loss of SOC, particularly the labile $\mathrm{C}$ fractions, due to unsuitable management practices can adversely affect soil physical properties. A well aggregated soil provides physical protection to SOC. Therefore, the maintenance of soil aggregation can help to sequester greater amounts of $\mathrm{C}$ in soils and improve soil quality. Therefore, the main objective of the present review study was to assess the impact of long-term manure and synthetic fertilization and residue retention on SOC storage, soil aggregation and responses of SOC fractions in the Typic Ustochept soil of Northwest India.

\section{Soil organic carbon storage}

SOC storage is usually measured in terms of total $\mathrm{C}$ stored, but how much $\mathrm{C}$ is stored and for how long this $\mathrm{C}$ can be stored depends on the pools (active/labile vs. recalcitrant/passive) and their cycling ( $\mathrm{Six}$ et 
al., 2001; Gleixner et al., 2002), form of stabilization (chemical/physical), and physical location (inter/intra-aggregate vs. free) (Six et al., 2001) of the $\mathrm{C}$ in the soil. Kanchikerimath and Singh, (2001) also found that inorganic fertilizers plus organic material increased the SOC content of the soil. The reasons for the higher SOC in manure soils at deeper depths include the following. First, the crop rooting depth between organic manure and inorganic fertilizer soils differ. The organic manure soils can be favorable for the growth of roots into deeper layers due to the relatively loose soil and high soil water content. Second, SOC in organic manure soils can also move to lower depths through earthworm burrows and leaching. Gami et al., (2009) also reported a significant increase in SOC stocks to $60 \mathrm{~cm}$ depth under three 23-25-year-old long-term fertility experiments in the Nepal, with application of manure and inorganic fertilizer. Within $1 \mathrm{~m}$ soil depth, the cumulative distribution of SOC in the CK, N, NP, FYM, $\mathrm{NP}+\mathrm{S}$ and $\mathrm{NP}+\mathrm{FYM}$ treatments were by $50 \%$, $46 \%, 51 \%, 53 \%, 54 \%$ and $55 \%$ in the $0-40$ $\mathrm{cm}$ layer, and $68 \%, 68 \%, 71 \%, 72 \%, 73 \%$ and $74 \%$ in the $0-60 \mathrm{~cm}$ layer, respectively. The SOC storage in the $60-100 \mathrm{~cm}$ layer was statistically similar among different treatments. On average the estimate of soil C accumulation to $60 \mathrm{~cm}$ depth were $267 \%$ and $41 \%$ greater than that for soil $\mathrm{C}$ accumulated to $20 \mathrm{~cm}$ depth and to $40 \mathrm{~cm}$ depth.

Liu et al., (2013) also found that the topsoil $(0-20 \mathrm{~cm})$ had the maximum levels of cumulative SOC storage in the $1 \mathrm{~m}$ soil depth for the CK, N, NP, FYM, NP+S and $\mathrm{NP}+\mathrm{FYM}$ treatments, accounting for $24 \%$, $23 \%, 27 \%, 30 \%, 31 \%$ and $31 \%$, respectively. At the $20-40 \mathrm{~cm}$ and $40-60 \mathrm{~cm}$ soil layers, the SOC stocks of the NP, FYM, NP+S and $\mathrm{NP}+\mathrm{FYM}$ treatments were significantly higher by $17 \%, 21 \%, 25 \%$ and $37 \%$ and $5.3 \%, 8.1 \%, 7.3 \%$ and $11 \%$, respectively, than that of the CK. The differences of SOC storage between different treatments were not significant in the $60-80 \mathrm{~cm}$ and $80-100 \mathrm{~cm}$ soil layers. SOC storages were significantly different between fertilization treatments in the $0-100 \mathrm{~cm}$ profile. Compared with the CK treatment, SOC storages of the NP+FYM, $\mathrm{NP}+\mathrm{S}, \mathrm{FYM}$ and NP treatments within the $0-$ $100 \mathrm{~cm}$ soil depth were increased by nearly $30,24,20$ and $12 \%$, respectively.

Song et al., (2015) reported that Soil organic $\mathrm{C}$ content was highest in the topsoil $(0-0 \cdot 2$ $\mathrm{m})$, and then decreased rapidly with soil depth (Fig. 1a). In the topsoil layer, SOC content in MNPK, FAL and SNPK was significantly higher than that in the unfertilized control by $50.7,25.6$ and $12.4 \%$, respectively, whereas no significant difference was found between the unfertilized control and NPK. In the subsoil $(0.2-0.4 \mathrm{~m})$ layer, SOC contents in MNPK and FAL were significantly higher than for the unfertilized control, NPK and SNPK, but no significant differences were observed among the unfertilized control, NPK and SNPK treatments. In the $0.4-0.6 \mathrm{~m}$ and 0.6-0.8m layers, MNPK had the highest SOC content among the treatments (Fig.1a). The increasing trend of $\mathrm{C}$ content in soils could be explained by the amount of $\mathrm{C}$ input. Firstly, soil mineralization rate is usually stable, thus the rate of SOC change is directly related to $\mathrm{C}$ input from organic amendments (Jastrow et al., 2007). The higher amount of organic matter input in MNPK and SNPK treatments promoted SOC concentration in the soil ( $\mathrm{Li}$ et al., 2010). Secondly, the average maize yields over the experimental duration in MNPK and SNPK treatments were significantly higher than in the unfertilized control consequently providing higher amounts of root residues and exudates in the soil (Fan et al., 2005). Therefore, higher organic matter and root biomass and exudation input in MNPK and SNPK treatments contributed to the increases in $\mathrm{C}$ content in the soil. In addition, straw incorporation concentrated less $\mathrm{C}$ in the soil 
compared to the MNPK treatment, which might have resulted from low soil temperature and moisture in this region, which restricted straw mineralization (Ogle et al., 2005). Moreover, the fractions of large- and macroaggregates in FAL were significantly higher than in the unfertilized control, NPK, SNPK and MNPK, whereas the fractions of microand silt +clay aggregates $(<53 \mu \mathrm{m})$ in FAL were significantly lower than in other treatments (Fig.1b). There were no significant differences in aggregate-size distribution among the unfertilized control, NPK, SNPK and MNPK treatments, except for the higher fraction of micro-aggregates and lower fraction of silt +clay aggregates in SNPK (Fig.1b). The proportion of aggregates $>250$ $\mu \mathrm{m}$ was similar and not significantly different to the proportion of aggregates $<250 \mu \mathrm{m}$ in the FAL treatment. However, the proportion of aggregates $<250 \mu \mathrm{m}$ in the unfertilized control, NPK, SNPK and MNPK treatments, ranging from 65.0 to $71.3 \%$, was significantly higher than the proportion of aggregates $>250$ $\mu \mathrm{m}$. Cropping practices lead to larger aggregate breakdown into smaller aggregates, thus, micro- and silt +clay aggregates are dominant in cropland soils (Liang et al., 2009).

Zhang et al., (2014) revealed that the sum of SOC storage in 0-60 cm layers with the three incorporation treatments were higher than CK, i.e., $7.71 \%, 11.14$ and $1.70 \%$ in 2008, $15.15 \%, 24.00 \%$ and $6.86 \%$ in 2009 , and $21.40 \%, 20.38 \%$ and $8.21 \%$ in 2010 , respectively (Fig.2a). The SOC storage increased with the number of years of incorporation, i.e., the SOC storage $(0-60 \mathrm{~cm}$ depth) in 2010 had increased by $6.19-12.48 \%$ compared with 2008, and decreased with the soil layer depth, i.e., by $3.75-25.68 \%$ in 2008 , $11.85-21.70 \%$ in 2009 and $13.51-26.64 \%$ in 2010. The SOC storage of $H$ and $M$ was slightly higher than CK in 2008, although the difference was significant in 40-60 cm layer only. In 2009, compared with CK, H and M significantly increased the SOC storage by $11.01 \%$ and $21.74 \%$ in $0-20 \mathrm{~cm}$ layer, $14.94 \%$ and $18.81 \%$ in $20-40 \mathrm{~cm}$ layer, and $20.40 \%$ and $32.47 \%$ in $40-60 \mathrm{~cm}$ layer, respectively, and $\mathrm{L}$ was significantly increased by $7.89 \%$ in $40-60 \mathrm{~cm}$ layer only. However, Fig. 2b shows that the fractal dimensions with the three incorporation treatments decreased significantly after three years of straw incorporation. The fractal dimensions $(0-40 \mathrm{~cm}$ layer $)$ with the incorporation treatments were lower than those of CK during 2008-2010, i.e., 0.16\%, $0.11 \%$ and $0.02 \%$ in $2008,0.14 \%, 0.16 \%$ and $0.06 \%$ in 2009 , and $0.24 \%, 0.26 \%$ and $0.06 \%$ in 2010, respectively. The fractal dimensions also increased with the soil layer depth and decreased with the number years of incorporation, i.e., the $\mathrm{H}, \mathrm{M}, \mathrm{L}$ and $\mathrm{CK}$ in 2010 was $0.20 \%, 0.27 \%, 0.17 \%$ and $0.12 \%$ higher than that in 2008. The fractal dimensions in the $0-10 \mathrm{~cm}$ layers with the four treatments were ranked in the order: $\mathrm{H}$, M, L, and $\mathrm{C} \mathrm{K}$ in 2008. The fractal dimensions with $\mathrm{H}$ and $\mathrm{M}$ were significantly lower than CK, i.e., $0.33 \%, 0.17 \%$ and $0.06 \%$, respectively.

Xie Jun-yu et al., (2015) reported that SOC storage in $<0.25 \mathrm{~mm}$ aggregates was not affected by nutrient management at both soil layers, except for the NPK treatment at 0-10 $\mathrm{cm}$ depth, which yielded significantly higher value than that of CK (Fig. 4a). However, SOC storage in soil aggregates treated with NP, NPK and MNPK was lower in >1 mm aggregates compared with those treated with CK at both soil depths. Higher SOC partitioning proportions were also observed in $0.25-1 \mathrm{~mm}$ aggregates at $0-10 \mathrm{~cm}$ and $0.25-$ $0.5 \mathrm{~mm}$ aggregates at $10-20 \mathrm{~cm}$ depth in soil treated with MNPK than those in CK (Fig. 3a). Moreover, total nitrogen (TN) concentrations in $1-2$ and $0.25-0.5 \mathrm{~mm}$ aggregates were higher under Abandonment 
than those under Cropping at $0-10 \mathrm{~cm}$ soil depth. Fallow showed significantly lower TN concentration in $>1 \mathrm{~mm}$ aggregates than Cropping and Abandonment. At 10-20 cm soil depth, TN concentrations in $>0.5 \mathrm{~mm}$ aggregates were significantly lower under Abandonment than those under Cropping (Fig. 3b).

Wang et al., (2020) also found that different return patterns had different effects on SOC storage (Fig. 4a). RR could significantly increase SOC storage by $10.1 \%, 8.7 \%$, and $8.0 \%$ when residues were returned once in a single cropping system (OSCS), in a double cropping system (ODCS) and twice in a double cropping system (TDCS) when compared to residue removal, respectively. When all residue from the previous growing season was returned to the field (All) and when only half the amount was returned (Half), the effects on SOC storage were similar, with a significant increase by $11.4 \%$ and $11.2 \%$, respectively. Residue return duration had a great impact on SOC storage. Short-term RR significantly increased SOC storage by $10.7 \%$, and this effect was slightly lower for medium-term RR which was $9.3 \%$. The effect of long-term RR was highest $13.5 \%$ (Fig. 4a). Residues from maize, wheat, and rice significantly increased SOC storage by $9.7 \%, 10.6 \%$, and $9.2 \%$, respectively however, return of different crop residues had little impacts on SOC storage. However, SOC storage was closely related to the cropping pattern (Fig.4b). After 6-10 yrs of RR without crop rotation, SOC storage increased highly significant $16.7 \%$, while after 6-10 yrs of RR with crop rotation, SOC storage slightly increased $(8.1 \%$. Compared to production without crop rotation, the application of crop rotation had a lower impact on the increase in SOC storage in $>5$ yrs of adoption of RR. As returning duration $>10 \mathrm{yr}$, SOC sequestration rate showed decline in fields without crop rotation, which shows that soil reached its maximum potential to store $\mathrm{C}$. This indicated the phenomenon of "C saturation". Regarding the cropping system, SOC storage dramatically increased in single cropping systems under RR 12.6\%. More SOC was consumed by crop growth in double cropping systems, and therefore, SOC storage was significantly increased by $10.1 \%$ under RR (Fig.4b). Cultivation of maize, wheat, and rice had similar effects on SOC storage under RR, with significant increases by $10.5 \%, 10.3 \%$, and $12.4 \%$, respectively.

Cai et al., (2016) showed that long-term manure application significantly increased SOC and total $\mathrm{N}$ content and enhanced $\mathrm{C}$ and $\mathrm{N}$ mineralization in the three particle-size fractions. The content of SOC and total $\mathrm{N}$ followed the order 2000-250 $\mu \mathrm{m}>250$ $53 \mu \mathrm{m}>53 \mu \mathrm{m}$ fraction, whereas the amount of $\mathrm{C}$ and $\mathrm{N}$ mineralization followed the reverse order. In the $<53 \mu \mathrm{m}$ fraction, the $\mathrm{M}_{60} \mathrm{NPK}$ treatment significantly increased the amount of $\mathrm{C}$ and $\mathrm{N}$ mineralized (7.0 and10.1times, respectively) compared to the $\mathrm{M}_{0} \mathrm{CK}$ treatment. Long-term manure application, especially when combined with chemical fertilizers, resulted in increased soil microbial biomass $\mathrm{C}$ and $\mathrm{N}$ [Fig. 5a and 5b].

Cai et al., (2016) also found that The TOC in 0-7.5 cm soil under integrated nutrient supply, except NPK+GR and NPK+SPM, was even greater than sole fertilizer treatments. At other soil depths also, TOC under these treatments was significantly greater than control, although the differences were not as spectacular as in the top soil [Fig.6a]. The SOC stock varied under different treatments from 26.9 to $30.8,17.7$ to $21.2,15.7$ to 23.3 and 7.21 to $9.82 \mathrm{Mg} \mathrm{ha}^{-1}$ at $0-15,15-30,30-45$ and $45-60 \mathrm{~cm}$ soil depth, respectively [Fig $6 a]$. The SOC stock decreased markedly with increasing soil profile depth irrespective of treatments. The higher SOC stock in the surface as compared to deeper soil layers may 
possibly be associated with $\mathrm{C}$ inputs through organic sources. Dou et al., (2005) reported that Soil microbial biomass $\mathrm{C}$ was more affected by tillage than by crop intensity or $\mathrm{N}$ fertilization in wheat, sorghum, and soybean systems [Fig. 6b]. In wheat systems, SMBC under NT was 18, 25, and $13 \%$ greater in CW, SWS, and WS, respectively, than with $\mathrm{CT}$ at 0 - to 5-cm depth, but was 26, 5, and $10 \%$ lower in CW, SWS, and WS, respectively, than with $\mathrm{CT}$ at $5-$ to $15-\mathrm{cm}$ depth.

\section{Water stable aggregates}

Ogunwole, (2008) revealed that soils amended with FYM +NPK had significantly more dry-sieved aggregates $>2.0 \mathrm{~mm}$ than the unamended and NPK amended soils. The mean water-stable aggregate fraction was highest for the $>2.0 \mathrm{~mm}$ size range, next was $<0.1 \mathrm{~mm}$ and lowest was for $0.5-2.0 \mathrm{~mm}$ size range. In the $>2.0 \mathrm{~mm}$ size range significantly higher water-stable aggregate fraction was recorded with FYM amended soil than all the other amended soils. In the $0.5-2.0 \mathrm{~mm}$ size range significantly greater water-stable aggregate fraction was recorded with NPK amended soil than the other treatments. At the $<0.1 \mathrm{~mm}$ size range the FYM+NPK amended soil had significantly higher aggregate fraction than the other treatments. The MWD of the water-stable aggregates was significantly lower for unamended soil and soils amended with FYM + NPK.

Whalen et al., (2003) reported that in 2000, the proportion of WSA $>4 \mathrm{~mm}$ was greater in soils receiving compost than soils that did not receive compost and there were fewer WSA $>0.25 \mathrm{~mm}$ in compost amended than unamended soils (Fig. 7). In addition, there were fewer WSA between 0.25 and $1 \mathrm{~mm}$ in compost-amended than unamended soils in 2001. Long-term applications of animal manure increased the soil organic $\mathrm{C}$ level and favor the formation of WSA $>0.25 \mathrm{~mm}$ under field conditions.

Zhang et al., (2014) also found that the average MWD and GMD values under the incorporation treatments were higher in the 0 $40 \mathrm{~cm}$ layers than CK during 2008-2010, i.e., $1.46-3.65 \%$ and $0.39-1.54 \%$ in $2008,1.09-$ $2.90 \%$ and $0.62-1.55 \%$ in $2009,1.77-11.35 \%$ and $0.77-3.83 \%$ in 2010, respectively (Fig.8a and $8 \mathrm{~b}$ ). The MWD and GMD values decreased with the soil layer depth and increased with the number of years of incorporation, i.e., the $\mathrm{H}, \mathrm{M}, \mathrm{L}$ and $\mathrm{CK}$ in 2010 was $10.56 \%$ and $3.04 \%$ (P, 0.05$), 7.47 \%$ and $2.29 \%, 3.24 \%$ and $1.15 \%$, and $2.92 \%$ and $0.77 \%$ higher than that in 2008. The MWD and GMD values of treatments in the $0-10$ and $10-20 \mathrm{~cm}$ layers were ranked in the order: $\mathrm{H}>\mathrm{M}>\mathrm{L}>\mathrm{CK}$. The MWD and GMD values in the $30-40 \mathrm{~cm}$ layers under the incorporation treatments were increased by $1.87 \%, 3.75 \%, 3.37 \%$ and $0.76 \%, 1.76 \%$, $0.78 \%$ in $2008,0.37 \%, 0.01 \%, 0.73 \%$ and $0.73 \%, 0.45 \%, 0.45 \%$ in $2009,8.09 \%, 7.35 \%$, $2.21 \%$ and $2.32 \%, 1.93 \%, 0.77 \%$ in 2010 , compared with $\mathrm{CK}$, respectively.

Aoyama et al., (1999) revealed that the largest portion of the OM occurred in the large micro-aggregates $(53-250 \mathrm{~mm}$ ) (Figs. 9a and $9 b)$. The amounts of both the particulate and mineral-associated $\mathrm{C}$ and $\mathrm{N}$ were greater in treatments receiving manure than in the nonmanured one. This was particularly true in the small macro-aggregates $(250-1000 \mathrm{~mm})$ reflecting the greater amounts of soil material and greater $\mathrm{C}$ and $\mathrm{N}$ concentrations in this fraction from the manured soils. The application of NPK also increased somewhat the particulate and mineral associated $\mathrm{C}$ and $\mathrm{N}$ in macro-aggregates. The amount of particulate $\mathrm{C}$ and $\mathrm{N}$ in any aggregate fraction was usually less than those of the mineralassociated, except for $\mathrm{C}$ in the large macro- 
aggregates $(>1000 \mathrm{~mm})$. The ratio of particulate/mineral-associated $\mathrm{C}$ or $\mathrm{N}$ decreased with decreasing aggregate size class. The different treatments had a significant effect on this ratio only for the aggregates $>1000 \mathrm{~mm}$.

Tripathi et al., (2014) also found that the aggregate size distribution was significantly affected by the application of FYM and inorganic fertilizers compared to unfertilized control. An aggregate fraction of $0.25-0.5$ $\mathrm{mm}$ made up the largest (27.36-31.36\%) whereas $0.1-0.053 \mathrm{~mm}$ fraction made the least contribution $(2.10-3.87 \%)$ in total WSA percentage at two sampling depths. Application of FYM alone or in combination with inorganic fertilizers significantly improved the formation of macro and mesoaggregates compared to unfertilized control increased the occurrence of macroaggregates $(5-2 \mathrm{~mm})$ by $165.33 \%$ whereas meso-aggregates increased by $130.68 \%$ in $2-1 \mathrm{~mm}$ fraction, by $282.83 \%$ in $1-0.5 \mathrm{~mm}$ fraction over unfertilized control in $0-15$ $\mathrm{cm}$ soil layer. The proportion of microaggregates $(0.25-0.1 \mathrm{~mm}$ and $0.1-0.053 \mathrm{~mm})$ was less in FYM + inorganic fertilized plots than the plots applied with inorganic fertilizer alone. The application of FYM decreased the micro-aggregate fraction of $0.25-0.1 \mathrm{~mm}$ by 0.35 to $9.94 \%$ and micro-aggregate fraction of $0.1-0.053$ by $0.4-30.63 \%$ compared to unfertilized control in the surface soil. The increase in the proportion of water stable macro-aggregates $(>2 \mathrm{~mm})$ by FYM + inorganic fertilizer application could be attributed to the input of additional organic residues and available $\mathrm{C}$ to the soils. Tian et al., (2018) reported that the increased organic carbon concentrations in each size fraction. Organic C concentrations in the <0.053-, 0.053 - to $0.25-, 0.25-$ to $2.0-$, and $>2.0-\mathrm{mm}$ fractions were 14.012.0, 14.4, 24.1\% greater, respectively, in $\mathrm{OF}$ than in $\mathrm{CF}$. Organics also significantly increased the organic $\mathrm{C}$ concentrations of micro-aggregates occluded with in macro-aggregates. Organic $\mathrm{C}$ concentrations in the $<0.053$ and 0.053 to 0.25 micro-aggregates were 14.0 and $13.8 \%$ greater, respectively, in OF than in CF. Moreover, the combining the four aggregate size classes, the total amount of soil organic C storage was $20 \%$ greater in OF $\left(5.60 \mathrm{~kg} \mathrm{~m}^{-2}\right)$ than in $\mathrm{CF}\left(4.67 \mathrm{~kg} \mathrm{~m}^{-2}\right)$.

\section{Labile and recalcitrant carbon pool}

Ghosh et al., (2018) reported that in both 015 and $15-30 \mathrm{~cm}$ soil layers, plots with NPK + FYM had significantly higher labile and recalcitrant $\mathrm{C}$ pools than control and NP plots (Fig. 10a). Plots with NPK + FYM also had higher labile $C$ than $150 \%$ NPK in the $15-$ $30 \mathrm{~cm}$ soil layer, but both plots had similar recalcitrant $\mathrm{C}$ pools. While NPK $+F Y M$ had significantly higher nonlabile $\mathrm{C}$ pool than all other treatments in soil surface, all plots had similar non-labile $\mathrm{C}$ pools in $15-30 \mathrm{~cm}$ soil layer. On average, the relative preponderance of the fractions of SOC, extracted under a gradient of oxidizing conditions was: Pool $4>$ Pool $1>$ Pool 3 (less labile C) > Pool 2 (labile C) in surface soil layer constituting about $33.4 \%$, $24.6 \%, 21.3 \%$ and $20.7 \%$, respectively, of the total SOC. However, macro-aggregates of NP plots in soil surface had 1.36 and 1.38 times greater SOC enrichment than $\mathrm{NPK}+\mathrm{FYM}$ and NPK treated plots. Whereas, macro-aggregates from $\mathrm{N}$ plots had 1.12 and 1.18 times greater $\mathrm{C}$ enrichment than $\mathrm{NPK}+\mathrm{FYM}$ and NPK plots, respectively, in sub-surface soil. Carbon enrichment factor of soil micro-aggregates from all plots were $<1$, indicating net $\mathrm{C}$ depletion (Fig. 10b).

Nayak et al., (2012) also found that the continuous application of FYM along with $\mathrm{N}-$ $\mathrm{P}-\mathrm{K}(\mathrm{NPK}+\mathrm{FYM})$ resulted in a significantly higher soil MBC over NPK. The MBC content of plots which received $\mathrm{CR}$ along 
with NPK $(\mathrm{NPK}+\mathrm{CR})$ was at par with NPK+ FYM. However, the MBC content of surface soil in NPK+GM treatments was significantly lower than NPK+ FYM, where it was at par. The MBC content of surface soil in NPK+ GM plots was at par with NPK + CR where it was significantly lower. The highest MBC content of $515.4 \mathrm{~g} \mathrm{~g}^{-1}$ at surface soil (0-15 $\mathrm{cm}$ ) was observed in NPK plots. Zhu et al., (2014) observed that the contents of soil TOC and labile organic C fractions, where PD generally had the highest contents of TOC, DOC, MBC and EOC at the three soil depths. Crop straw return treatments (PR, PW, PD, RR, RW, RD) had consistently higher amount of TOC and labile organic $\mathrm{C}$ fractions at the three soil depths than without crop straw return treatments (PN, RN). Moreover, PN had significantly lower TOC, DOC, MBC and EOC at $0-7 \mathrm{~cm}$ and 7-14 $\mathrm{cm}$, and RN had the lowest TOC and MBC at 14-21 cm compared to other treatments.

Das et al., (2016) revealed that among the OOC fractions, $\mathrm{C}_{\mathrm{VL}}$ in the 0-7.5, 7.5-15 and $15-30 \mathrm{~cm}$ soil depths was in the range1.02$2.51, \quad 0.72-2.09$ and $0.58-1.15 \mathrm{gkg}^{-1}$ respectively, with corresponding mean values of $1.71,1.43$ and $0.90 \mathrm{~g} \mathrm{~kg}^{-1}$. At the $0-7.5$ $\mathrm{cm}$ soil depth, the lowest $\mathrm{C}_{\mathrm{VL}}$ was seen in the unfertilized control treatment $\left(1.02 \mathrm{~g} \mathrm{~kg}^{-1}\right)$ and CVL increased significantly under IPNS treatments, with particularly high values (2.51 $\mathrm{g} \mathrm{kg}^{-1}$ ) under the NPK + GR +FYM treatment. This treatment also had the highest CVL values at the 7.5-15 and 15-30 $\mathrm{cm}$ depths $\left(2.09\right.$ and $1.15 \mathrm{~g} \mathrm{~kg}^{-1}$ respectively). At $7.5-15$ and $15-30 \mathrm{~cm}$ soil depths, the lowest CVL values were observed under the NPKZn treatment $(0.72$ and $0.58 \mathrm{~g}$ $\mathrm{kg}^{-1}$ respectively) rather than in the unfertilized control. Compared with uncultivated soil, the $\mathrm{C}_{\mathrm{VL}}$ content was lower under control or NPKZn treatments, but was invariably greater under treatments using combinations of FYM, GR or SPM with NPK fertilizers. The percentage change in CVL over uncultivated soil varied from-38\% to $109 \%$ at different depths. However, the $\mathrm{C}_{\mathrm{NL}}$ content at the $0-7.5,7.5-15$ and $15-30 \mathrm{~cm}$ soil depths varied, with values in the range $7.23-10.07,6.73-8.63$ and $4.30-6.40$ $\mathrm{g} \mathrm{kg}^{-1}$ respectively, and corresponding mean values of $7.99,7.73$ and $5.39 \mathrm{~g} \mathrm{~kg}^{-1}$.

Averaged across treatments, the $\mathrm{C}_{\mathrm{NL}}$ content at the $0-7.5$ and $7.5-15 \mathrm{~cm}$ depths was similar, but decreased significantly at the15$30 \mathrm{~cm}$ soil depth. Averaged across soil depths, $\mathrm{C}_{\mathrm{NL}}$ content under the NPK + CR and $\mathrm{NPK}+\mathrm{GR}+\mathrm{FYM}$ treatments (7.99 and 7.63 $\mathrm{g} \mathrm{kg}^{-1}$ respectively) were significantly higher than in the other treatment groups. Compared with uncultivated soil, the change in $\mathrm{C}_{\mathrm{NL}}$ under different nutrient supply options was inconsistent, although $\mathrm{C}_{\mathrm{NL}}$ content increased under the NPK + CR treatment by $25-33 \%$ at the $0-7.5$ and $7.5-15$ depths. Considering overall mean values across soil depths and nutrient supply options, the abundance of these four OOC fractions was in the order $\mathrm{C}_{\mathrm{NL}}\left(7.04 \mathrm{gkg}^{-1}\right)$ $>\mathrm{C}_{\mathrm{L}}\left(2.02 \mathrm{gkg}^{-1}\right)>\mathrm{C}_{\mathrm{VL}}\left(1.35 \mathrm{gkg}^{-1}\right)>\mathrm{C}_{\mathrm{LL}}$ $\left(0.75 \mathrm{~g} \mathrm{~kg}^{-1}\right)$.

Mazumdar et al., (2015) reported that organic $\mathrm{C}$ distribution in soil profile differed significantly among the treatments and with depths. At the surface $(0-15 \mathrm{~cm})$ layer, NPK+FYM contained the highest SOC concentration (7.7 $\left.\mathrm{gkg}^{-1}\right)$ followed by $\mathrm{NPK}+\mathrm{CR}\left(7.5 \mathrm{gkg}^{-1}\right)$ and NPK+GM (7.4gkg$\left.{ }^{1}\right)$. There was a significant reduction in SOC concentration with the sole application of inorganic fertilizers (NPK) compared with those in the mixed organic and inorganic treatments. The lowest SOC concentration (3.6 $\left.\mathrm{g} \mathrm{kg}^{-1}\right)$ in $0-15 \mathrm{~cm}$ layer was observed in treatment of a continuous cropping of ricewheat over 25 years without any amendments. Mean SOC concentration in the profile increased from $2.4 \mathrm{~g} \mathrm{~kg}^{-1}$ in control to 
4.1 $\mathrm{g} \mathrm{kg}^{-1}$ in NPK+FYM. All the treatments showed higher accumulation of SOC in surface layer. Significant variations in SOC content were also observed in the sub-soil layers; mean SOC content decreased from 6.4 at surface $0-15 \mathrm{~cm}$ to $1.8 \mathrm{~g} \mathrm{~kg}^{-1}$ at $45-60 \mathrm{~cm}$ soil layer. Fertilizer application has played an important role in improving the total SOC and labile $\mathrm{C}$ pools content in the soil.
Because there was low SOC content in the Northwest of India, the long-term application of organic manure and inorganic fertilizer increased the content of SOC. SOC concentrations and storage were highest in surface soil and depth interval down to $60 \mathrm{~cm}$ under $\mathrm{NP}+\mathrm{FYM}$ and $\mathrm{NP}+\mathrm{S}$, below which concentrations did not change with depth.

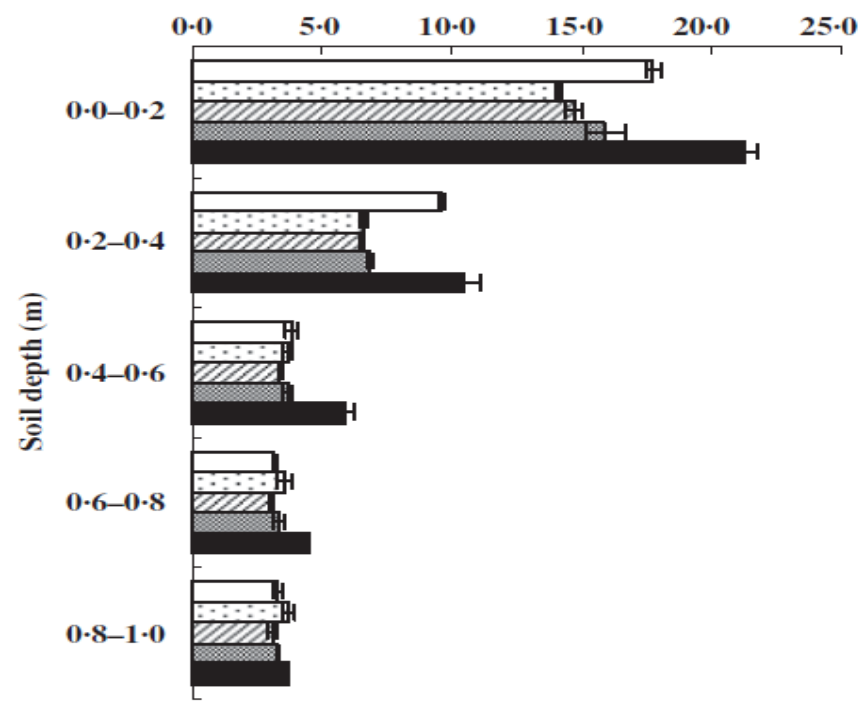

(a)

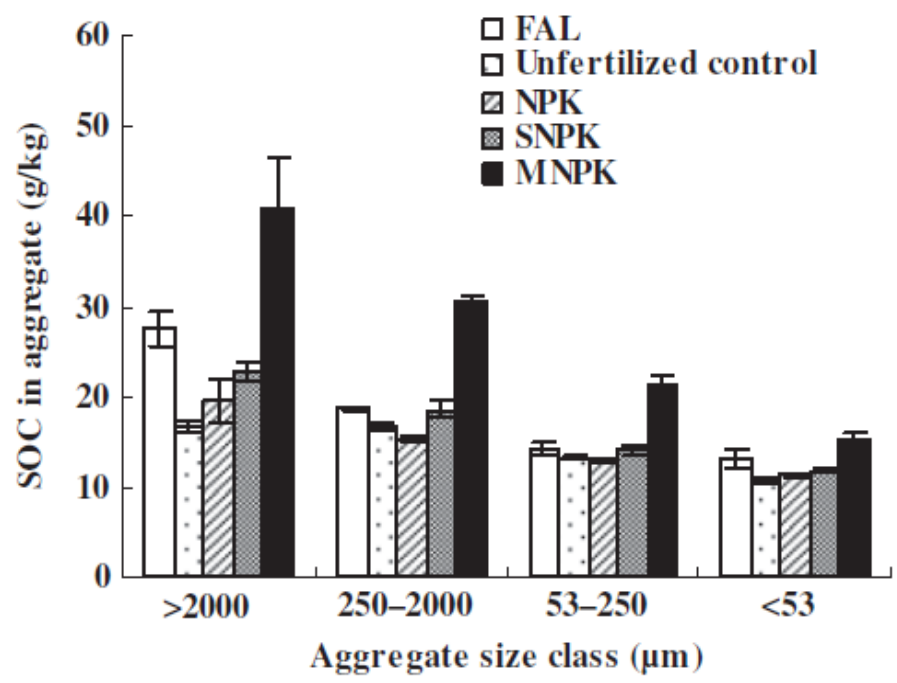

(b)

Fig.1 (a) Soil organic carbon (SOC) contents in top 1.0m soil under different fertilization treatments. NPK, balanced inorganic N, P, K fertilizers; SNPK, balanced inorganic fertilizers plus maize straw residues; MNPK, balanced inorganic fertilizers plus farmyard manure

(b)Soil aggregate distribution in the topsoil $(0-0.2 \mathrm{~m})$ under different treatments 


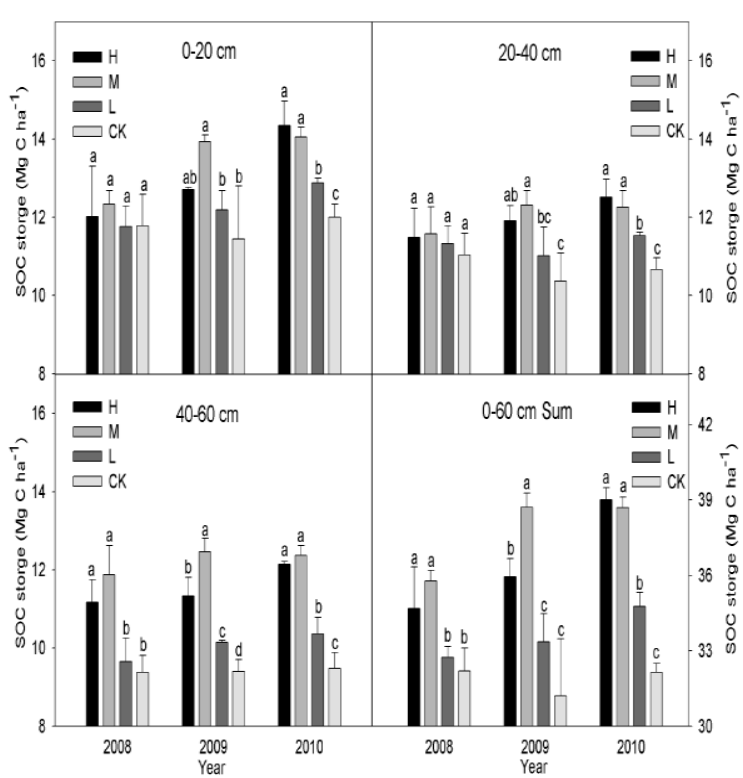

(a)

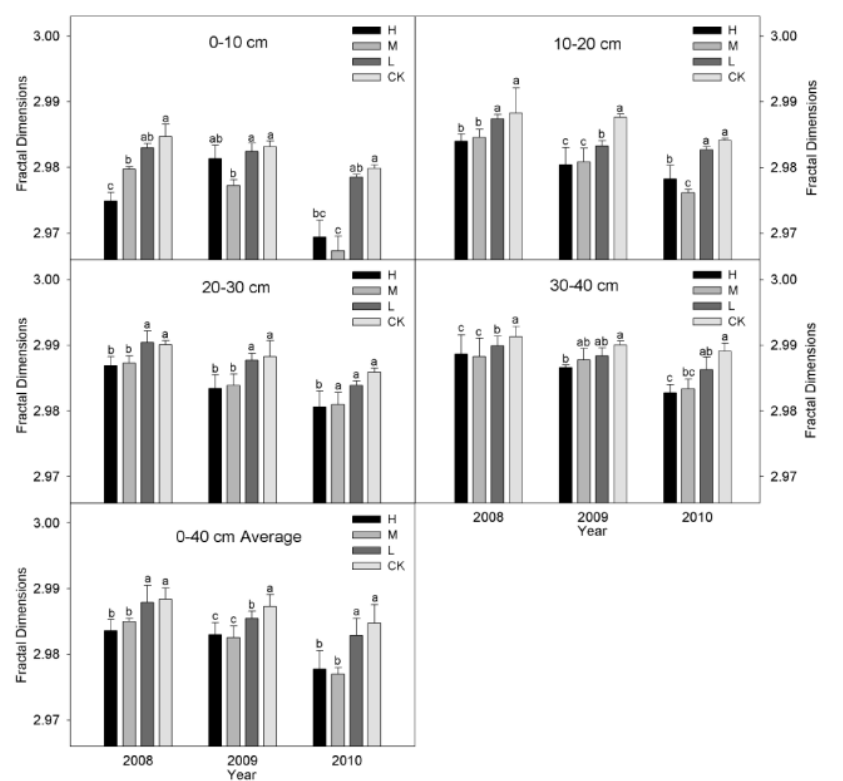

(b)

Fig.2 (a) Soil organic carbon storage with different straw incorporation treatments $\left(\mathrm{Mg} \mathrm{C}^{-1}\right)$

(b) Fractal dimensions (D) of soil aggregates with different straw incorporation treatments
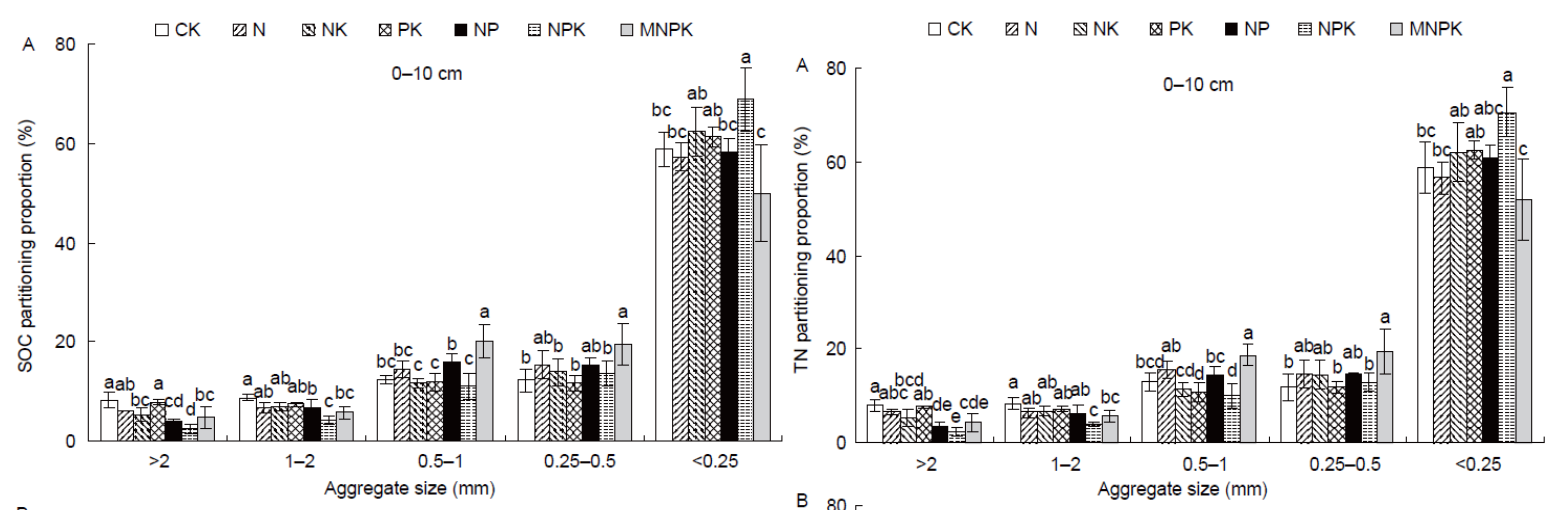

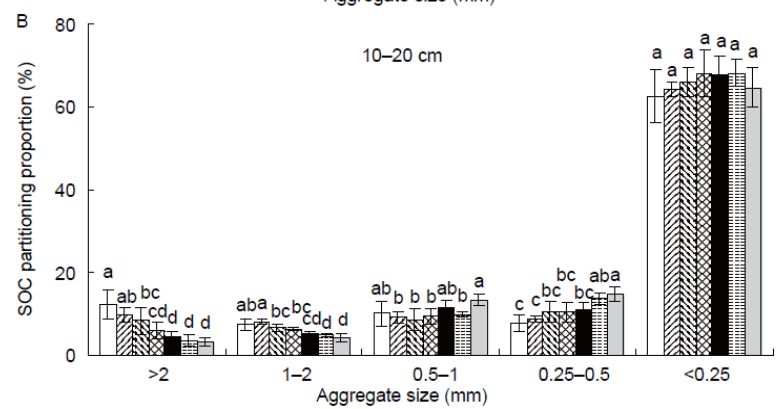

(a)

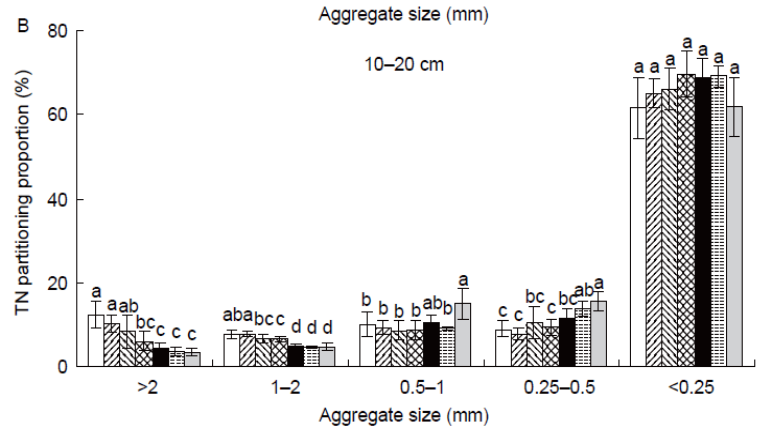

(b)

Fig.3 (a) Soil organic carbon (SOC) partitioning proportions (\%) in water-stable aggregates in 0$10 \mathrm{~cm}(\mathrm{~A})$ and $10-20 \mathrm{~cm}$ (B) soil horizons under different fertilizer treatments. CK, no nutrient input; N, nitrogen only; NK, nitrogen and potassium; PK, phosphorus and potassium; NP, nitrogen and phosphorus; NPK, nitrogen, phosphorus and potassium; MNPK, manure plus NPK (b) Total nitrogen (TN) partitioning proportions (\%) in water-stable aggregates in $0-10 \mathrm{~cm}(\mathrm{~A})$ and $10-20 \mathrm{~cm}(\mathrm{~B})$ soil horizons under different fertilizer treatments 


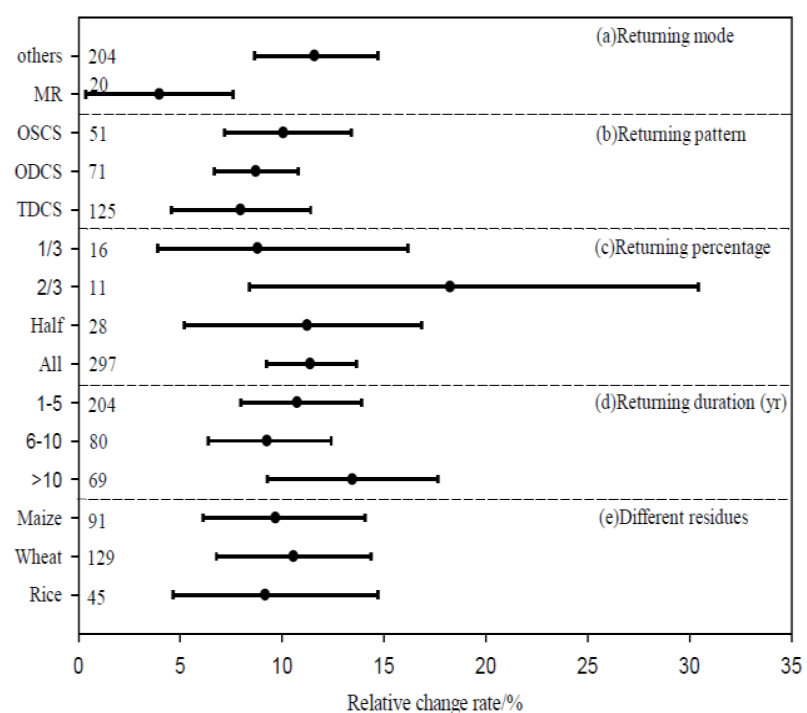

(a)

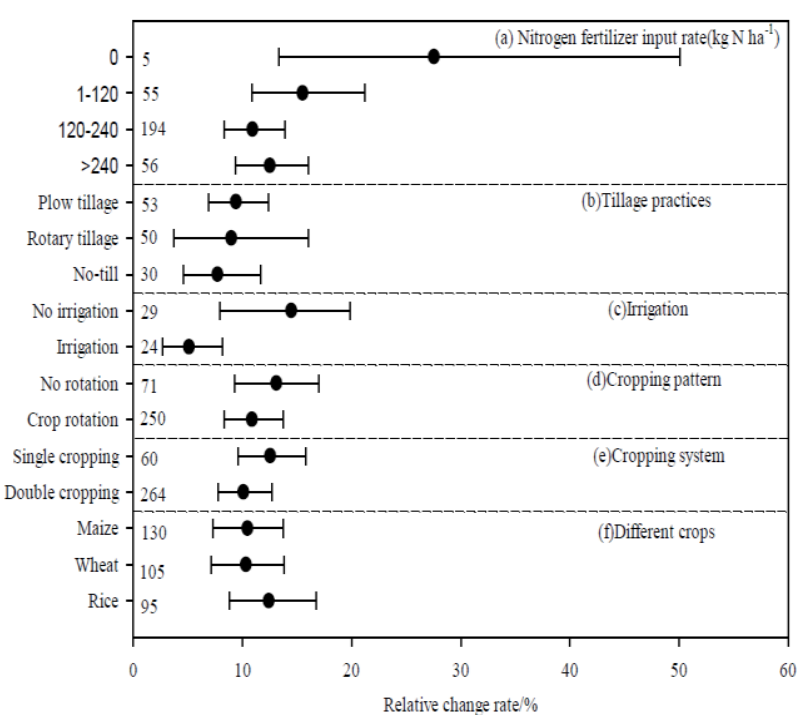

(b)

Fig.4 (a) Relative change rate of SOC storage responding to residue retention (b) Relative change rate of SOC storage responding to residue retention under field management practices
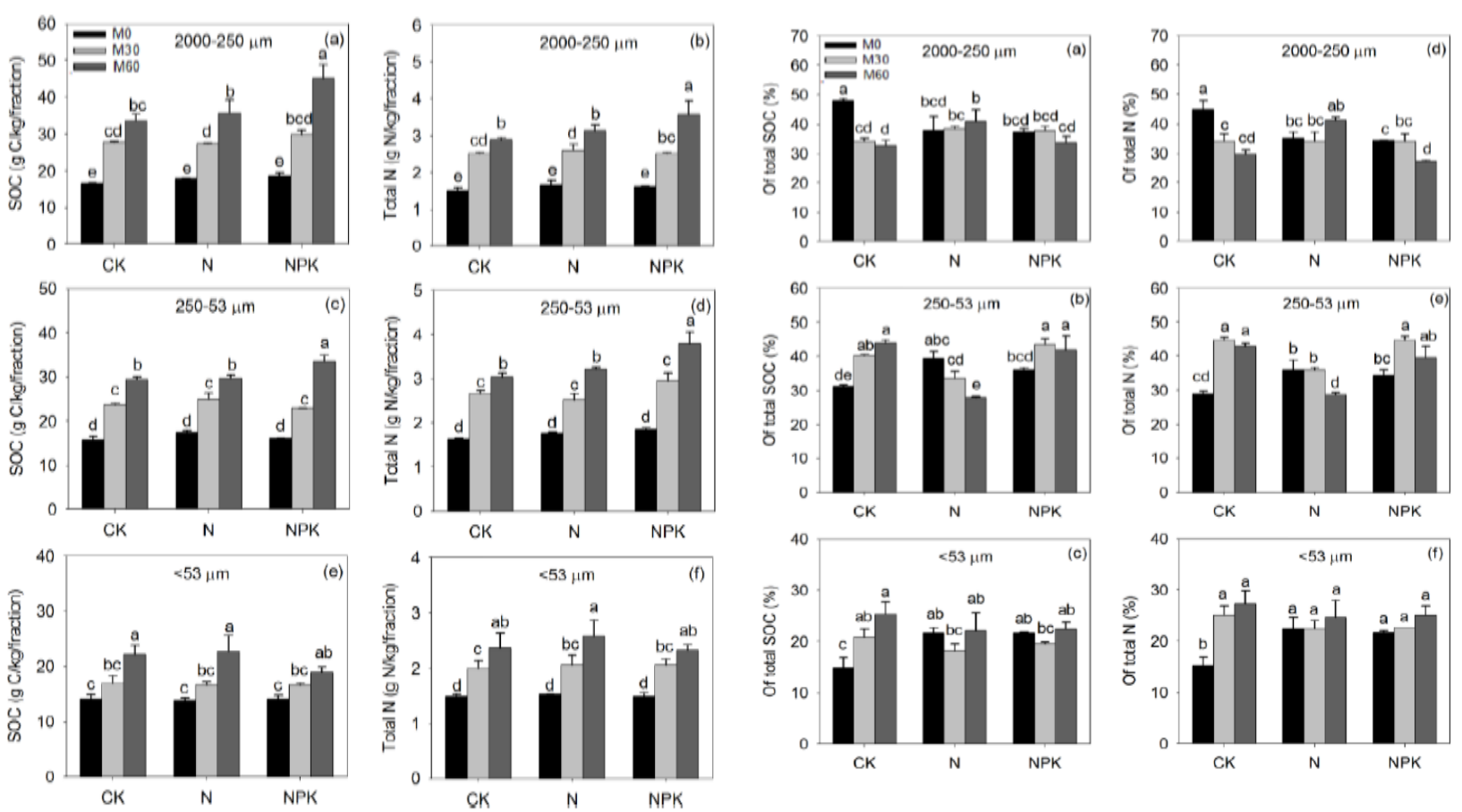

(a)

(b)

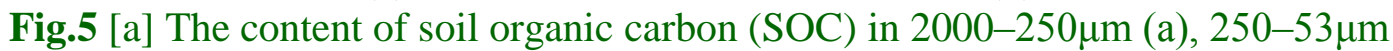

(c), $<53 \mu \mathrm{m}$ (e) fraction and total nitrogen (N) in $2000-250 \mu \mathrm{m}(\mathrm{b}), 250-53 \mu \mathrm{m}$

(d), $<53 \mu \mathrm{m}$ (f) fraction from the control (CK); [b] The percent (\%) of soil organic carbon (SOC) in $2000-250 \mu \mathrm{m}(\mathrm{a}), 250-53 \mu \mathrm{m}(\mathrm{c}),<53 \mu \mathrm{m}(\mathrm{e})$ fraction and total nitrogen $(\mathrm{N})$ in $2000-250 \mu \mathrm{m}$ (b), $250-53 \mu \mathrm{m}(\mathrm{d}),<53 \mu \mathrm{m}$ (f) fraction from the control (CK) 


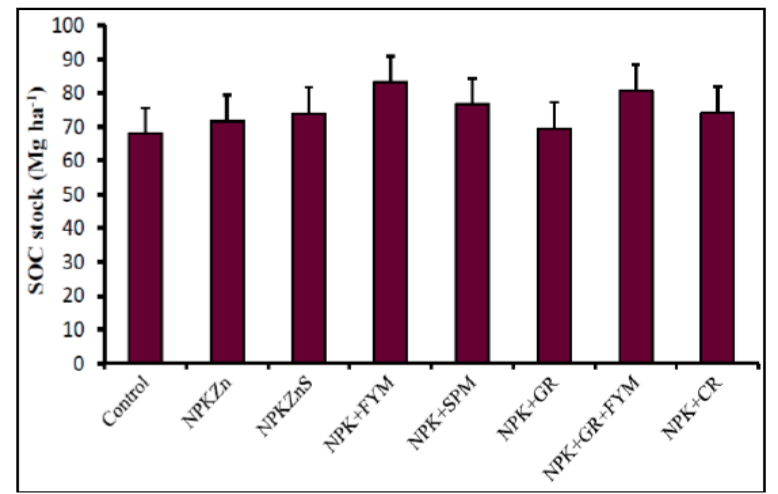

(a)

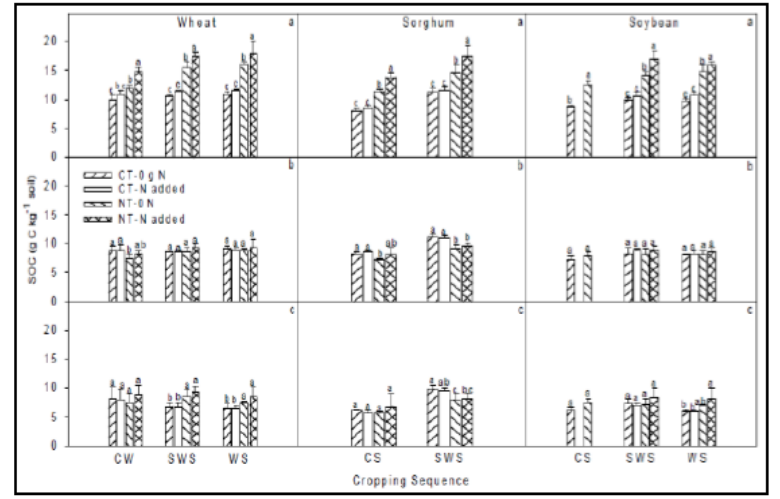

(b)

Fig.6 (a) Effect of long-term fertilization and manuring on SOC stock (0-60 cm soil depth) in rice-wheat system; (b) Soil microbial biomass C (SMBC) a); proportion of SOC as soil microbial biomass $\mathrm{C}$ (SMBC)

2000

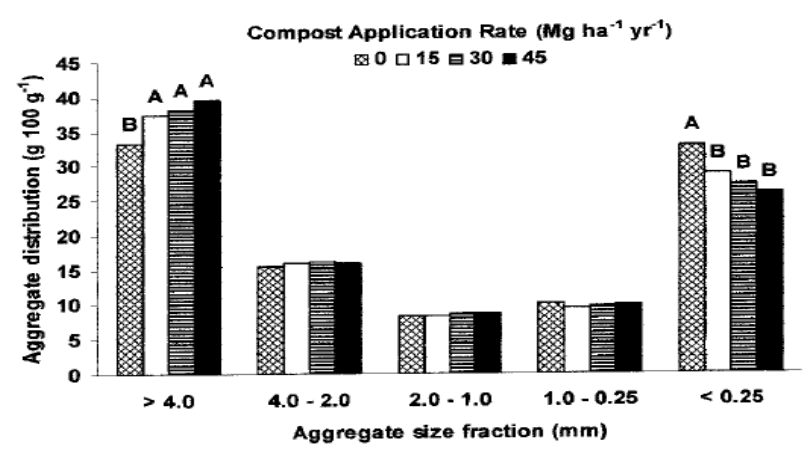

2001

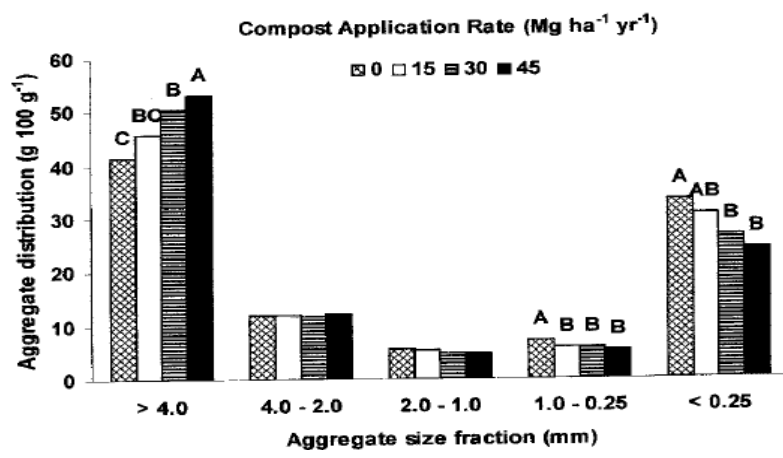

Fig.7 Effect of compost applications on the distribution of water- stable aggregates in 2000 and 2001

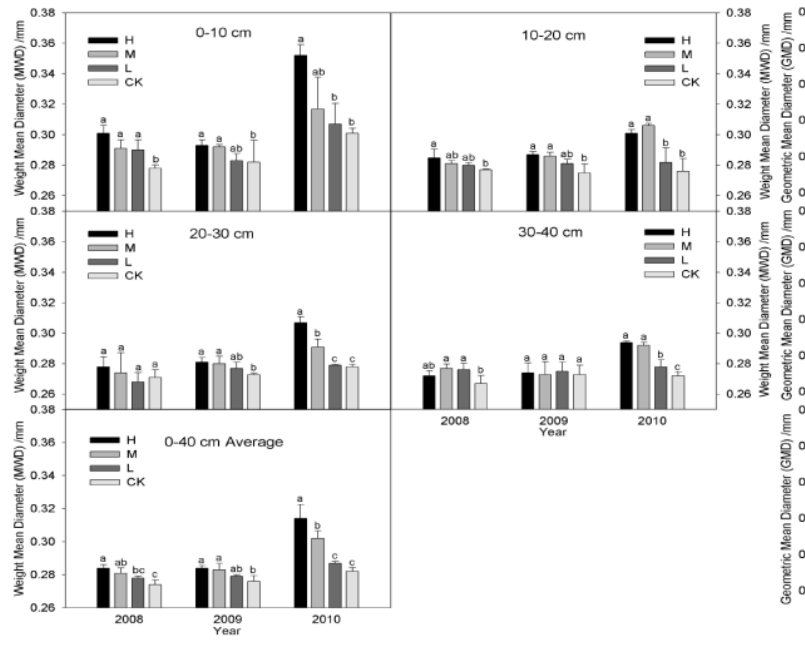

(a)

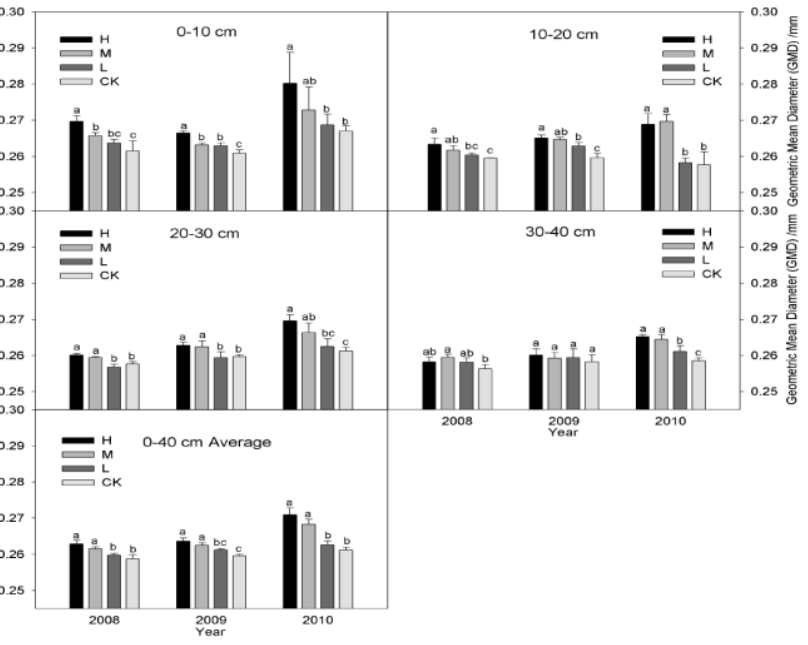

(b)

Fig.8 (a) MWD values with wet sieving under the different straw incorporation treatments (b) GMD values with wet sieving under the different straw incorporation treatments 


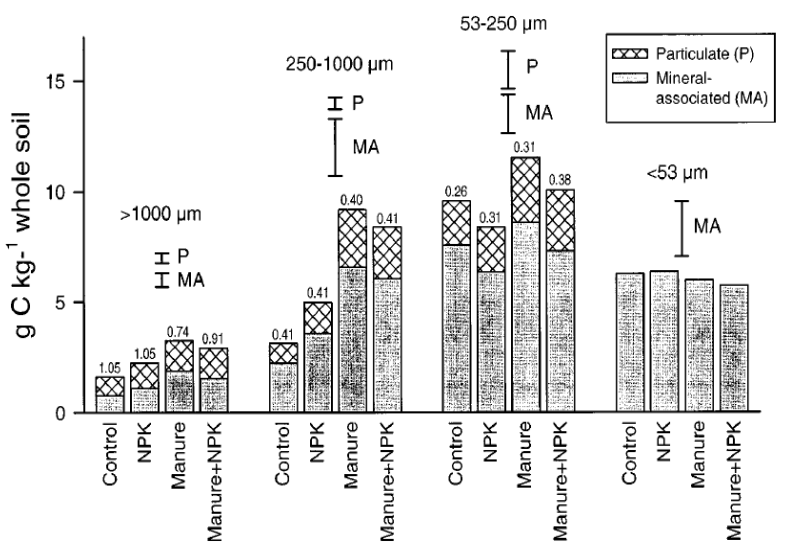

(a)

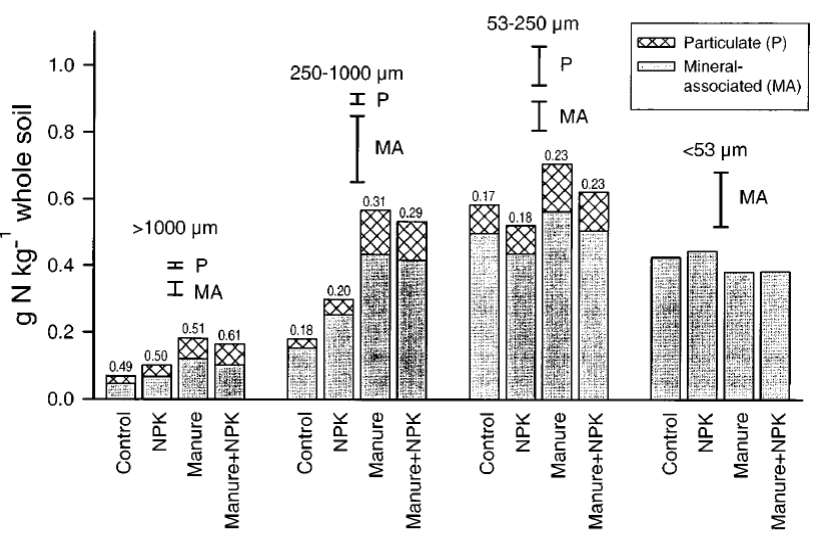

(b)

Fig.9 (a) Amount of particulate and mineral-associated C per $\mathrm{kg}$ of whole soil

(b) Amount of particulate and mineral-associated $\mathrm{N}$ per $\mathrm{kg}$ of whole soil

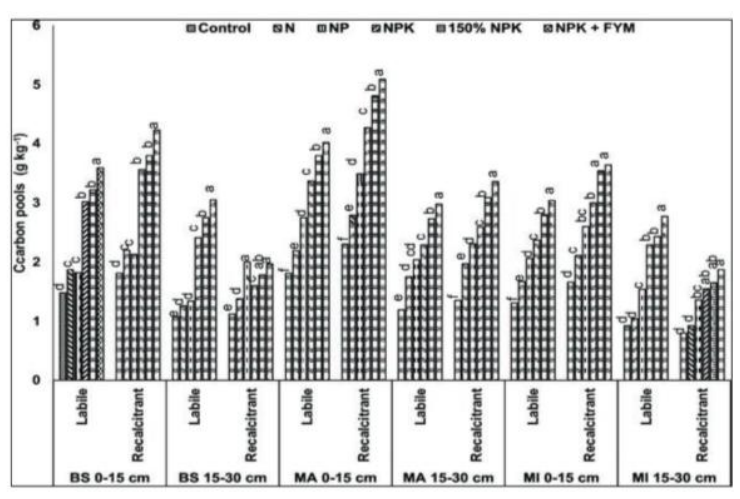

(a)

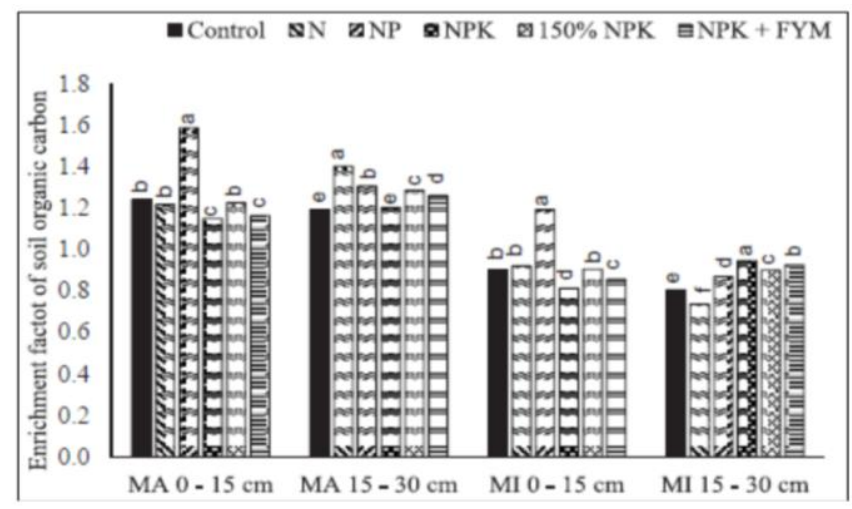

(b)

Fig.10 (a) Labile and recalcitrant carbon pools in bulk soils and aggregates as affected by longterm fertilization in the $0-15$ and $15-30 \mathrm{~cm}$ soil layers under a wheat-based cropping system in an Inceptisol; (b) Enrichment factor of soil organic C (SOC) in aggregates of fertilization under a wheat based cropping system in an Inceptisol. MA: Macro-aggregates, MI: Micro-aggregates, MA 0-15 cm: Macro-aggregates of 0-15 cm soil depth.

At the same time, on average the estimate of soil $\mathrm{C}$ storage to $60 \mathrm{~cm}$ depth was higher than that for soil $\mathrm{C}$ accumulated to $20 \mathrm{~cm}$ depth and to $40 \mathrm{~cm}$ depth, respectively. These findings suggest that the estimate of soil $\mathrm{C}$ accumulation to $60 \mathrm{~cm}$ depth was more effective than that for soil $\mathrm{C}$ accumulated to $20 \mathrm{~cm}$ depth and to $40 \mathrm{~cm}$ depth. NP+FYM were the most efficient management system for sequestering SOC. A large amount of $\mathrm{C}$ was also sequestered in soil under $\mathrm{NP}+\mathrm{S}$ treatment. Soil microbial biomass C, POC and DOC were all significantly greater under organic manure (farmyard manure or straw) plus inorganic fertilizers, especially in the surface. The labile fraction organic $\mathrm{C}$ contents decreased significantly with increasing soil depth. These labile pools were highly correlated with each other and SOC, indicating that they were sensitive to changes in SOC.

Any type of soil and crop management practices that could enhance carbon contents in soils should be considered and recommended for farmers' practice. Use of crop residues, animal manures, balanced fertilization and many other available organic 
sources may replenish and increase carbon stock in soils and bring multitude of benefits for agricultural sustainability. Long-term fertilization significantly influenced SOC concentrations and storage to $60 \mathrm{~cm}$ depth. Below $60 \mathrm{~cm}$, SOC concentrations and storages were statistically not significant between all treatments. The concentration of SOC at different depths in $0-60 \mathrm{~cm}$ soil profile was higher under NP+FYM follow by under $\mathrm{NP}+\mathrm{S}$, compared to under $\mathrm{CK}$. The SOC storage in $0-60 \mathrm{~cm}$ in $\mathrm{NP}+\mathrm{FYM}, \mathrm{NP}+\mathrm{S}$, FYM and NP treatments were increased by $41.3 \%, \quad 32.9 \%, \quad 28.1 \%$ and $17.9 \%$, respectively, as compared to the $\mathrm{CK}$ treatment. Organic manure plus inorganic fertilizer application also increased labile soil organic carbon pools in $0-60 \mathrm{~cm}$ depth. The organic and synthetic fertilizers increased total SOC concentrations due to substantial increments not only in the macro-aggregates and labile $\mathrm{C}$ pools, but also in the microaggregates and recalcitrant $\mathrm{C}$ pools. Increased labile and recalcitrant $\mathrm{C}$ in aggregates under organic and synthetic fertilizers is of specific importance, as it would reduce $\mathrm{CO}_{2}$ emission from soils. Organic and synthetic fertilizers also had a positive effect on the redistribution of SOC among the particle-size fractions, with obvious depletion of SOC in fine particles and pronounced enrichment in macroaggregates. However, the enrichment factors of SOC in macro-aggregates of all treatments were $>1$ and that of micro-aggregates were $<1$ in both soil layers, indicating $\mathrm{C}$ sequestration in macro-aggregates and $\mathrm{C}$ depletion from micro-aggregate

The integrated and organic treatments significantly increased the SOC fractions as compared to the chemical fertilizers alone. This suggests that the inclusion of organic manures in fertilization programs can enhance $\mathrm{C}$ sequestration in soils. The sensitivities or changes of labile $\mathrm{C}$ fractions (WSC, MBC,
LFC and POM) were much greater than the SOC following the application of fertilizers and/or FYM. Thus, the labile fractions of $\mathrm{C}$ may be used as indicators of change in $\mathrm{C}$ accumulation following application of fertilizers and/or manures. The application of fertilizers and/or FYM provided another benefit of increase in soil aggregates, which will provide physical protection to SOC resulting in less $\mathrm{C}$ emissions from agricultural soils. The SOC storage, $0.25 \mathrm{~mm}$ macroaggregates, MWD and GMD also increased with higher straw incorporation rates. The fractal dimension decreased with increasing straw incorporation rates. The sensitivities or changes of labile $\mathrm{C}$ fractions (WSC, MBC, LFC and POM) were much greater than the SOC following the application of fertilizers and/or FYM. Thus, the labile fractions of $\mathrm{C}$ may be used as indicators of change in $\mathrm{C}$ accumulation following application of fertilizers and/or manures. The application of fertilizers and/or FYM provided another benefit of increase in soil aggregates, which will provide physical protection to SOC The large scale implementation of the straw or manure plus inorganic fertilizer amendments will help to enhance the capacity of carbon sequestration in the region. Therefore, local government should encourage farmers to manage the nutrients and soil fertility based on integrated nutrient management by combining organic matter with inorganic fertilizer to improve soil carbon pools for long-term.

\section{References}

Aoyama, M., Angers, D.A., and Dayegamiye, A.N. 1999. Particulate and mineralassociated organic matter in waterstable aggregates as affected by mineral fertilizer and manure applications. Can. J. Soil. Sci. 79: 295302.

Banger K, Toor GS, Biswas A, Sidhu SS, and 
Sudhir K. 2010. Soil organic carbon fractions after 16-years of applications of fertilizers and organic manure in a Typic Rhodalfs in semi-arid tropics. Nutr Cycl Agroecosyst 86:391-399.

Cai A, Xu H, Shao X, Zhu P, Zhang W, Xu M et al., 2016. Carbon and Nitrogen Mineralization in Relation to Soil Particle-Size Fractions after 32 Years of Chemical and Manure Application in a Continuous Maize Cropping System. PLoS ONE, 11(3): e 0152521. doi: 10.1371

Das D, Dwivedi BS, Singh VK, Datta SP, Meena MC, Chakraborty D et al., 2016. Long-term effects of fertilizers and organic sources on soil organic carbon fractions under a rice-wheat system in the Indo-Gangetic Plains of northwest India. Soil

Res.http://dx.doi.org/10.1071/SR 16097

Dou F. 2005. Long-term Tillage, Cropping Sequence, and Nitrogen Fertilization Effects on Soil Car bon and Nitrogen Dynamics. Ph. D. Thesis, Zhejiang Agricultural University, Hangzhou, China.

Fan, T., Stewart, B. A.,Wang, Y., Luo, J., and Zhou,G. Y. 2005. Long-term fertilization effects on grain yield, water-use efficiency and soil fertility in the dryland of Loess Plateau in China. Agric Ecosyst Environ., 106:313-329.

Gami SK, Lauren JG, Duxbury JM. 2009. Soil organic carbon and nitrogen stocks in Nepal long-term soil fertility experiments. Soil Tillage Res 106: 95-103.

Ghosh A, Bhattacharyya R, Meena MC, Dwivedi BS, Geeta Singh, Agnihotri, R et al. 2018. Long-term fertilization effects on soil organic carbon sequestration in an Inceptisol. Soil Tillage Res. 177:134-
144.

Jastrow, J. D., Amonette, J.E., and Bailey, V. L. 2007. Mechanisms controlling soil carbon turnover and their potential application for enhancing carbon sequestration. Climatic Change 80: 523.

Kanchikerimath M, Singh D. 2001. Soil organic matter and biological properties after 26 years of maizewheat-cowpea cropping as affected by manure and fertilization in a Cambisol in semiarid region of India. Agric Ecosyst Environ 86: 155-162.

Li, Z., Liu, M., Wu, X., Han, F., and Zhang, T. 2010. Effects of long-term chemical fertilization and organic amendments on dynamics of soil organic $\mathrm{C}$ and total $\mathrm{N}$ in paddy soil derived from barren land in subtropical China. Soil Tillage Res., 106: 268-274.

Liang, A., Yang, X., Zhang, X., Mclaughlin, N., Shen, Y., and Li, W. 2009. Soil organic carbon changes in particlesize fractions following cultivation of Black soils in China. Soil Tillage Res., 105: 21-26.

Liu, E., Yan, C., Mei, X., Zhang, Y., and Fan, T. 2013. Long-Term Effect of Manure and Fertilizer on Soil Organic Carbon Pools in Dryland Farming in Northwest China. PLoS ONE 8(2): e56536. doi:10.1371/journal.pone. 0056536

Mazumdar SP, Kundu DK, Nayak AK, Ghosh D. 2015. Soil Aggregation and Associated Organic Carbon as Affected by Long Term Application of Fertilizer and Organic Manures under Rice-Wheat System in Middle Gangetic Plains of India. J Agri. Phy.15 (2):113-121.

Nayak AK, Gangwar B, Shukla AK, Mazumdar SP, Kumar A et al., 2012. Long-term effect of different integrated nutrient management on 
soil organic carbon and its fractions and sustainability of rice-wheat system in Indo Gangetic Plains of India. Field Crop Res.127:129-139.

Ogle, S. M., Breidt, F. J., and Paustian, K. 2005. Agricultural management impacts on soil organic carbon storage under moist and dry climatic conditions of temperate and tropical regions. Biogeochem., 72: 87-121.

Ogunwole JO. 2008. Soil Aggregate Characteristics and Organic Carbon Concentration after 45 Annual Applications of Manure and Inorganic Fertilizer. Biol Agri Hort, 25:223233.

Song, Z.W., Zhu, P., Gao, H.J., Peng, C., Deng, A.X., Zheng, C.Y., Mann, M.A., Islam, M.N., and Zhang, W.J. 2015. Effects of long-term fertilization on soil organic carbon content and aggregate composition under continuous maize cropping in Northeast China. J Agri Sci., 153: 236-244.

Tian XM, Fan H, Zhang FH, Wang KY, Ippolito JA, Li JH et al. 2018. Soil Carbon and Nitrogen Transformations under Soybean as Influenced by Organic Farming. Agro J. 110(5):1883-1892.

Tripathi R, Nayak K, Bhattacharyya P, Shukla AK, Shahid M, Raja R et al., 2014. Soil aggregation and distribution of carbon and nitrogen in different fractions after 41 years long-term fertilizer experiment in tropical rice-rice system. Geoderma., 213:280-286.

Wang, X., He,C., Liu, B., Zhao, X., Liu, Y., Wang, Q., and Zhang, H. 2020. Effects of Residue Returning on Soil Organic Carbon Storage and Sequestration Rate in China's Croplands: A Meta-Analysis. Agronomy,10: 691; doi:10.3390

Whalen, J.K., Hu, Q., and Liu, A. 2003. Compost Applications Increase WaterStable Aggregates in Conventional and No-Tillage Systems. Soil Sci. Soc. Am. J. 67:1842-1847.

Xie, Jun-Yu.,, Xu Ming-Gang., Qiangjiu Ciren., Yang Yang, Zhang Shu-Lan, Sun Ben-Hua, and Yang Xue-Yun. 2015. Soil aggregation and aggregate associated organic carbon and total nitrogen under long-term contrasting soil management regimes in loess soil. J Integ Agric., 14 (12): 2405-2416.

Zhang P, Wei T, Jia Z, Han Q, Ren X, et al., 2014. Effects of Straw Incorporation on Soil Organic Matter and Soil Water-Stable Aggregates Content in Semiarid Regions of Northwest China. PLoS ONE 9(3): e92839. doi:10.1371/journal.pone.0092839

Zhu L, Hu N, Yang M, Zhan X, Zhang Z. 2014. Effects of Different Tillage and Straw Return on Soil Organic Carbon in a Rice-Wheat Rotation System. PLoS ONE. 9(2):e88-900. Doi: $10.1371 /$ journal. pone. 0088900

\section{How to cite this article:}

Singh. P. K., R. K. Naresh, U. P. Shahi, S. S.Tomar, R. B. Singh, K. G. Yadav, Mukesh Kumar, Mukesh Kumar, A. K. Mishra, Vipin Kumar Sharma and Rakesh Tiwari. 2020. Effects of Manure and Synthetic Fertilizer with Residue Returning on Soil Organic Carbon Storage; Interactions with Intra-Aggregate Pore Structure and Water Stable Aggregates in High Input Cropping System: A Review. Int.J.Curr.Microbiol.App.Sci. 9(06): 2877-2892. doi: https://doi.org/10.20546/ijcmas.2020.906.348 